\title{
Cyclic Cumulative Damaging of Reinforced Concrete in Post-Peak Regions
}

\author{
Koichi Maekawa ${ }^{1}$ and Khaled Farouk El-Kashif ${ }^{2}$
}

Received 3 January 2004, accepted 13 March 2004

\begin{abstract}
Repetition of higher stresses apparently causes progressive damage, which is also strain/stress rate-dependent. This paper aims to separate time-dependent cumulative nolinearity and the effect of repetition of strain path on the overall damage evolution of concrete in compression. Cyclic uniaxial compression tests of concrete were conducted and timedependent plasticity and stiffness degradation were subtracted from total stress-strain relations to purely extract the effect of repeated stress cycle. Coupling of time dependency and authentic cyclic accumulation of damage was examined by both material and structural experiments especially in post-peak regions, and its applicability was experimentally verified mainly under low cyclic $(\mathrm{N}<100)$ actions. The high cycle $(\mathrm{N}>100)$ fatigue life predicted by the proposed constitutive law was also verified in terms of the $\mathrm{S}-\mathrm{N}$ curve.
\end{abstract}

\section{Introduction}

As far as material properties are concerned, a cyclic deterioration of concrete is clearly evident in compression, and low cycle $(\mathrm{N}<100)$ fatigue modeling has been empirically presented (Gao and Hsu 1998, Hsu 1981, Hwan 1991) mainly for seismic analyses. It is also generally known that reinforced concrete members exhibit stable restoring force characteristics in flexure before their capacity (Mutsuyoshi and Machida 1985) but the structural deterioration caused by repeated loads becomes predominant after their peak capacities. Here, it must be noted that the post-peak stress strain relation is to a great extent time-dependent. The post-peak cyclic responses and stress decay are also dependent on the strain rate as well as the number of repetitions in nature. When the strain rate or frequency of repeated stress is changed, the apparent cyclic responses of material vary accordingly. The authors understand that cyclic stressstrain relation after the strength shall be formulated with regard to time for post-peak analyses.

For extracting the authentic damage progress solely caused by repeated actions, systematically arranged experiments under different frequency are required, or a reasonably accurate time-dependent constitutive model is indispensable. Actually, time-dependent nonlinearity also grows during cyclic loading especially under higher strains. This paper is to subtract the time-dependent evolution of nonlinearity from the overall cyclic stressstrain relations by using a time-path dependent elastoplastic and damaging model for concrete, and the main

${ }^{1}$ Professor, Department of Civil Engineering, University of Tokyo, Japan

Email: maekawa@concrete.t.u-tokyo.ac.jp

${ }^{2}$ Post Doctoral Fellow, Department of Civil Engineering University of Tokyo, Japan focus is on post-peak behaviors.

Repeated stress creates additional plastic strain and a gradual decay of unloading stiffness in the pre-peak conditions, as shown in Fig. 1a. The stress was applied to concrete specimens by a universal-type machine popularly used for the standardized compressive strength test. In this experiment, it is not necessary to keep the stress or strain rates constant for extracting the evolution rates of nonlinearity but the precise measurement of induced stress and strain in time domain are rather critical for model formation and verification before and after the peak capacity. It should be kept in mind that both plasticity and unloading \& reloading stiffness degradation (defined as "damaging") go forward even under constantly sustained stress states. Then, the apparent nonlinearity results from both timedependent evolution and iteration of straining.

The computed strain based on the time-dependent constitutive model (El-Kashif and Maekawa 2003, 2004), which does not include the effect of stress repetition, is shown in Fig. 1a. In this case, about $75 \%$ of the strain progress is attributed to time-dependent nonlinearity and the rest, or $25 \%$, is rooted in repetition of stresses. When the maximum total strain is kept unchanged under cyclic loads in the post-peak region (see Fig. 1b), stress decay is experienced with advanced plasticity. A similar tendency is seen in the relaxation path where the total strain is kept constant. Thus, subtraction of time dependency is necessary to make sure the effect of stress or strain repetition. Figure 1c shows the combined path of cyclic creep and relaxation. The evolution of plasticity and damaging can be seen in this path, too.

In this study, a time-dependent elasto-plastic and damaging model for concrete is implemented to assess pure time-dependent deformation so that the unmixed effect of stress or strain iteration can be identified. As it is crucial to verify the knowledge from structural post- 

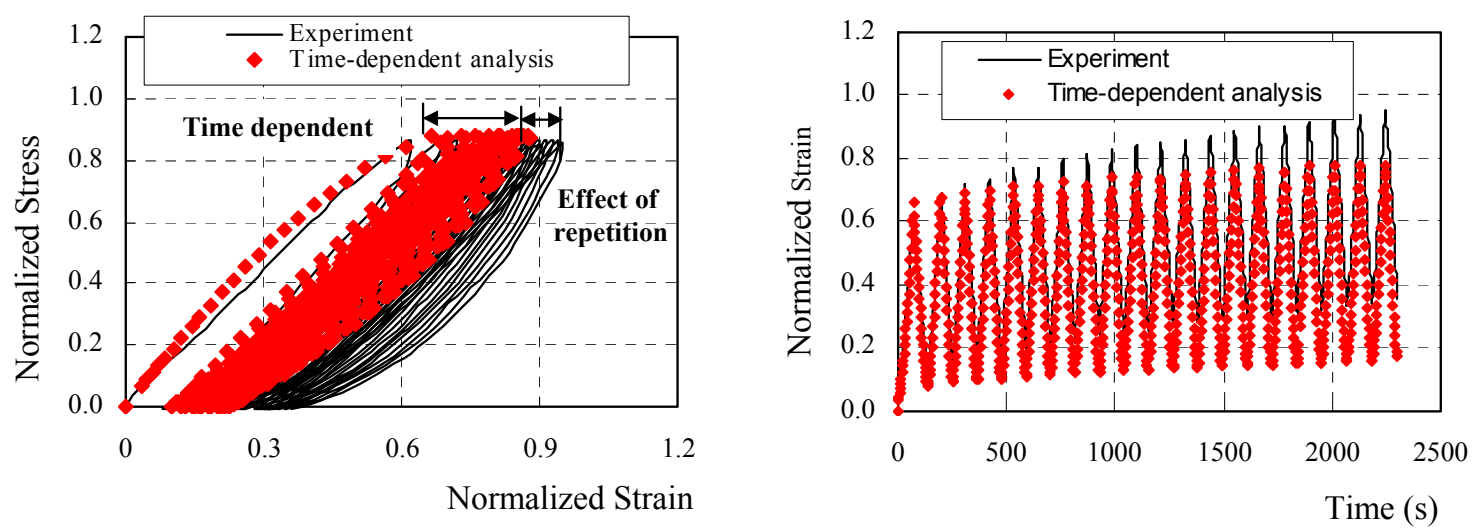

(a) Cyclic creep path

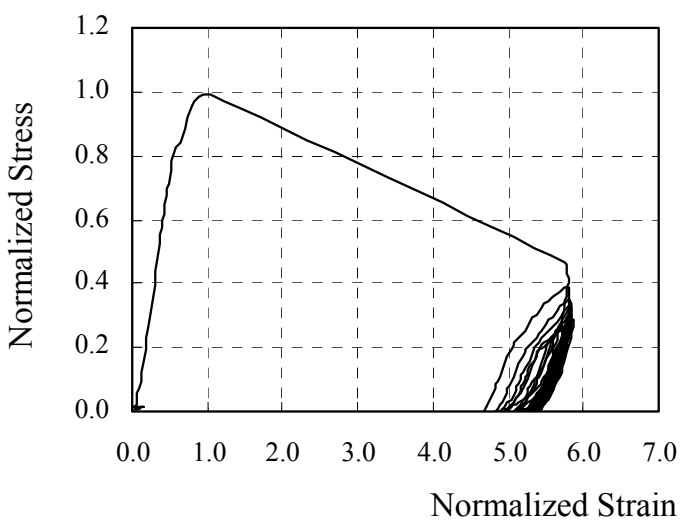

(b) Cyclic relaxation in the post-peak

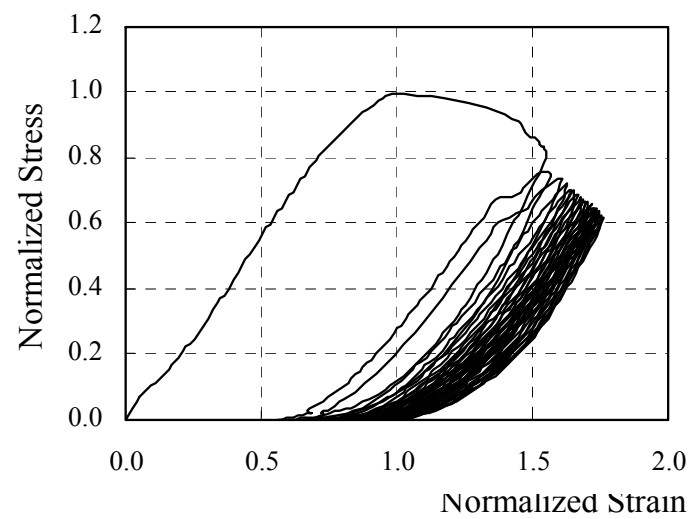

(c) Combined strain creep and stress relaxation

Fig. 1 Time-dependent cyclic stress strain relation of concrete in compression (normalized by uniaxial compressive strength and its strain).

peak responses, post-peak behaviors of in-plane shear walls subjected to different loading rates are used for multiple checking of modeling.

\section{Time-dependent elasto-plastic and cyclic progressive damaging}

This chapter aims to import the progressive damaging purely caused by repetition of strain paths into the previously formulated time-dependent elasto-plastic and damaging model (El-Kashif and Maekawa 2003, 2004). First, a basic scheme of the time-dependent constitutive model is reviewed and structural experimental verification of modeling is presented. Second, the effect of cyclic path is formulated.

\subsection{Time-strain path dependency}

The proposed modeling for time-dependent nonlinearity consists of plastic and damage evolution rules (ElKashif and Maekawa 2003, 2004, Maekawa and Li 1984) as,

$$
\varepsilon=\varepsilon_{e}+\varepsilon_{p}, \sigma=E_{o} \mathrm{~K} \varepsilon_{\mathrm{e}}+\sigma_{\text {loop }}
$$

$$
\begin{aligned}
& d \varepsilon_{p}=\left(\frac{\partial \varepsilon_{p}}{\partial t}\right) \mathrm{dt}+\left(\frac{\partial \varepsilon_{p}}{\partial \varepsilon_{e}}\right) \mathrm{d} \varepsilon_{e}, \\
& d K=\left(\frac{\partial K}{\partial t}\right) \mathrm{dt}+\left(\frac{\partial K}{\partial \varepsilon_{e}}\right) \mathrm{d} \varepsilon_{e} \\
& \sigma_{\text {loop }}=E_{\text {loop }}\left(\varepsilon_{\mathrm{e}}\right) \cdot \varepsilon_{\mathrm{e}}
\end{aligned}
$$

where, $K=$ fracture parameter, $\varepsilon_{\mathrm{e}}=$ elastic strain, $\varepsilon_{\mathrm{p}}=$ plastic strain, $\sigma=$ total stress, $\sigma_{\text {loop }}=$ additional loop stress, $\mathrm{t}=$ time, $E_{o}=$ initial elastic modulus and $E_{\text {loop }}=$ reversible modulus of elasticity. For simplicity of notation, the above stress and strain are defined as normalized ones by the uniaxial compressive strength and the corresponding strain, respectively.

Similar to the theory of plasticity, it was experimentally explored that plastic and fracturing potentials $\left(F_{p}\right.$, $F_{k}$ ) exist, on which the derivatives with respect to the elastic strain increment in Eq. (2) reveal non-zero (Tabata and Maekawa 1984). As the nonlinearity also proceeds with $\mathrm{d} F_{p}=0$ and $\mathrm{d} F_{k}=0$, the general formulation can be derived as, 


$$
\begin{aligned}
& \left(\frac{\partial \varepsilon_{p}}{\partial \varepsilon_{e}}\right)=0 \quad \text { when } \mathrm{F}_{\mathrm{p}}>0, \\
& \left(\frac{\partial \varepsilon_{p}}{\partial \varepsilon_{e}}\right)=-\left(\partial F_{p} / \partial \varepsilon_{e}\right) /\left(\partial F_{p} / \partial \varepsilon_{p}\right) \quad \text { when } \mathrm{F}_{\mathrm{p}}=0 \\
& \left(\frac{\partial K}{\partial \varepsilon_{e}}\right)=0 \quad \text { when } \mathrm{F}_{\mathrm{k}}<0, \\
& \left(\frac{\partial K}{\partial \varepsilon_{e}}\right)=-\left(\partial F_{k} / \partial \varepsilon_{e}\right) /\left(\partial F_{k} / \partial K\right) \quad \text { when } \mathrm{F}_{\mathrm{k}}=0
\end{aligned}
$$

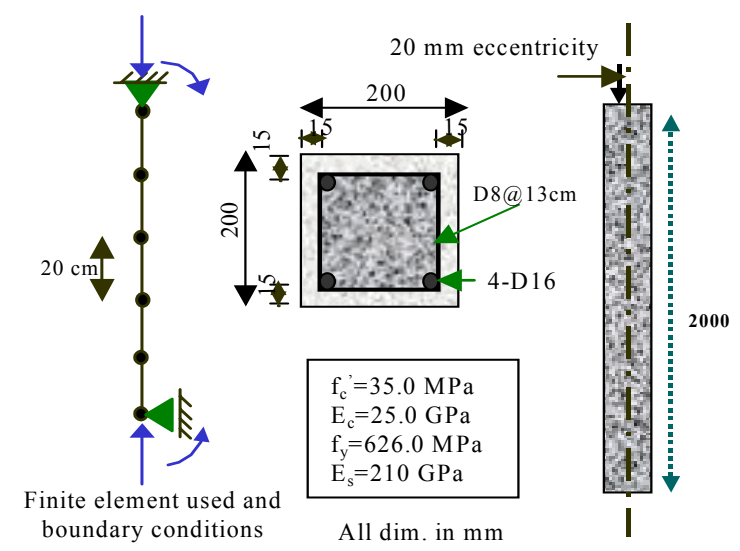

(a) Column details

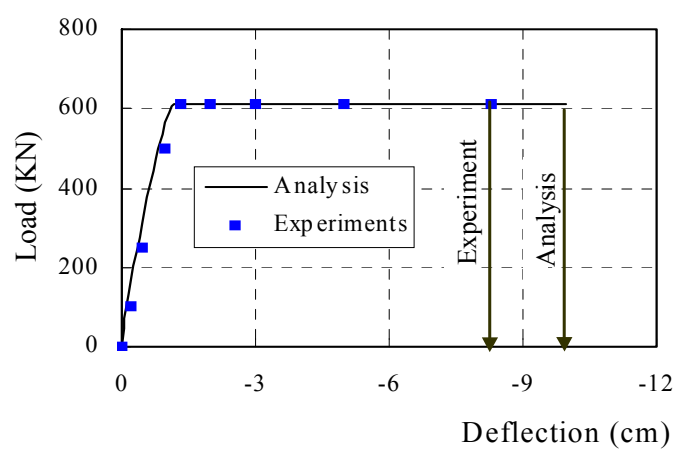

(b) Load deflection curve

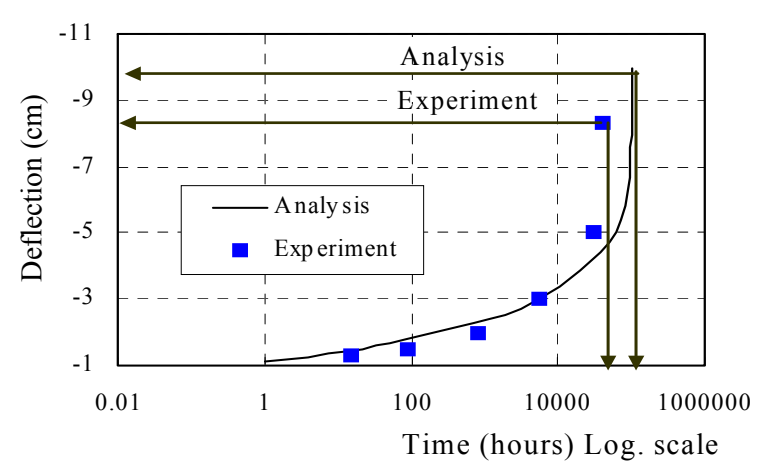

(c) Time-deflection curve

Fig. 2 Delayed creep failure of RC column in eccentric compression (large geometrical nonlinearity).
By using Eq. (4), we can identify the path-dependent derivatives in terms of elastic strain. The authors use the plastic and damage potentials $\left(F_{p}, F_{k}\right)$ formulated by Okamura and Maekawa (1991). For derivatives with respect to time in Eq. (2), plastic and fracturing rate models were presented under both pre and post-peak conditions (El-Kashif and Maekawa 2003). The term of loop stress expresses the nonlinear stress-strain relation in unloading/reloading loops and the secant nonlinear elastic modulus $E_{\text {loop }}$ is given with regard to the elastic strain (Maekawa et al. 2003) and the fracture parameter $K$ at the updated time. As the potential functions, rate models and nonlinear secant stiffness are given in reference (El-Kashif and Maekawa 2003), each formulation is skipped in detail.

The constitutive model was experimentally verified by using plain concrete specimens and over-reinforced concrete beams in flexure, but the main point was directed to short term ( $1 \mathrm{~s}$ to $1000 \mathrm{~s}$ ) behaviors. Longerterm (about a year) nonlinearity under higher stresses is also verified in this paper. Figure 2 shows the long RC column subjected to eccentric compression (Claeson and Gylltoft 2000). Reinforcement was made up of 4 deformed $16 \mathrm{~mm}$ bars and $8 \mathrm{~mm}$ stirrups at a distance of $13 \mathrm{~cm}$ with 656.0 and $466.0 \mathrm{MPa}$, respectively. The clear concrete cover was $15 \mathrm{~mm}$ and additional reinforcement was provided to prevent the failure in the anchorage zones. Because of eccentricity of loading, failure is accelerated due to additional moment caused by the additional displacement in the middle span of the column. For transient nonlinear analysis, the timedependent constitutive law in Eqs. (1-4) was imported in the fiber finite element (Maekawa et al. 2003). Figure 2 shows the comparison of the experimental results and analytical ones. A fair agreement is seen for the short column represented by the monotonic loading.

Figure 3 gives the short column subjected to eccentric compression by Viest et al. (1956) and the computed transient process of column deflection and applied loads is presented. The experimental data is reported only at the states of collapse. Geometrical nonlinearity is comparatively small enough to directly check the validity of the time-dependent material model. The constant rates of load exhibit different load-displacement curves, which are well simulated. Under the sustained load, delayed creep failure was recognized and its elapsed time to failure is reasonably predicted.

\subsection{Cumulative damaging by cyclic strain paths}

Repeated mechanical action is known to introduce the extension of crack ligament into solid continua. The Paris law for fatigue life prediction is formulated based upon the fact that the incremental crack propagation per unit cycle of action is proportional to the amplitude of the stress intensity factor which represents the local elastic stress state close to the tip of a single crack. For concrete continuum, assembly of distributed microcracks has to be treated before the peak capacity, and the 


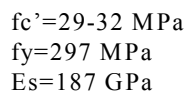

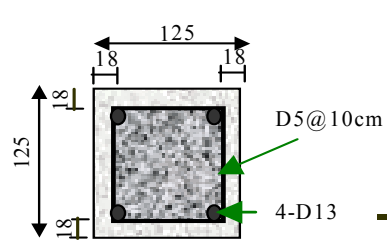

Sec A-A

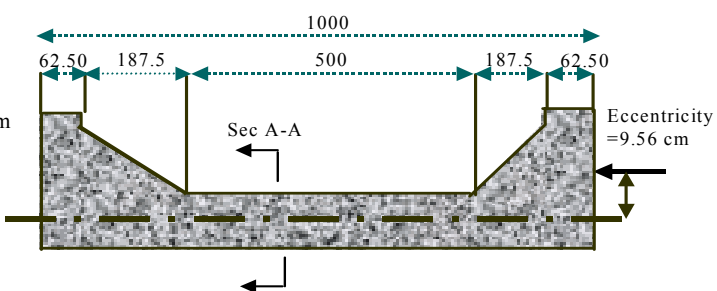

(a) Column details
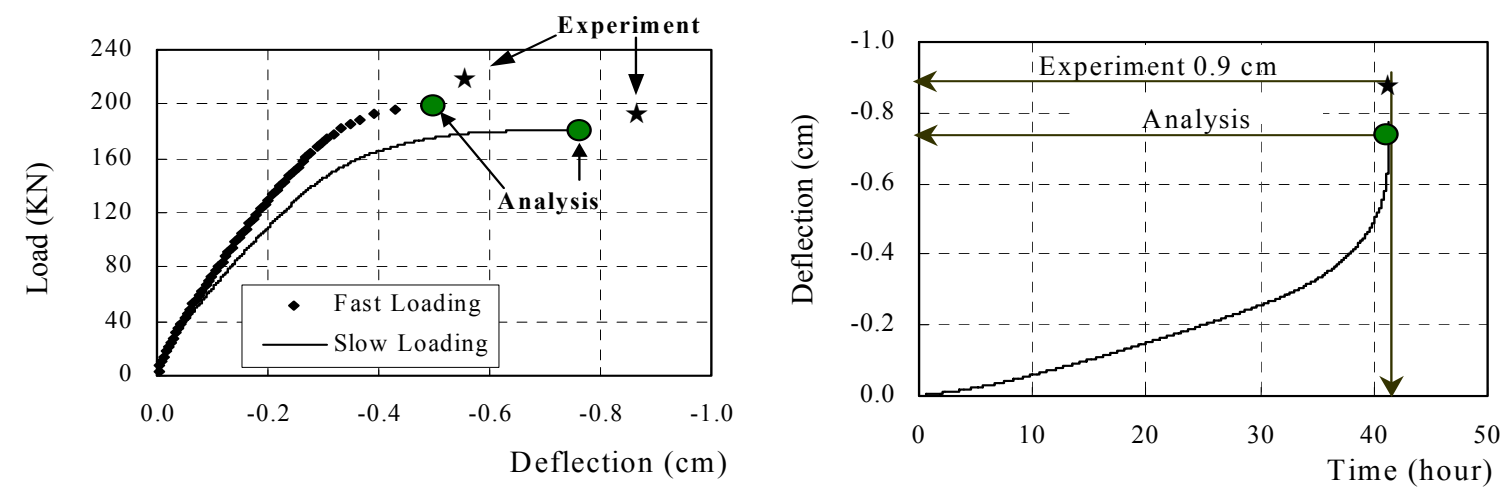

(b) Experimental and analytical results for different loading rate
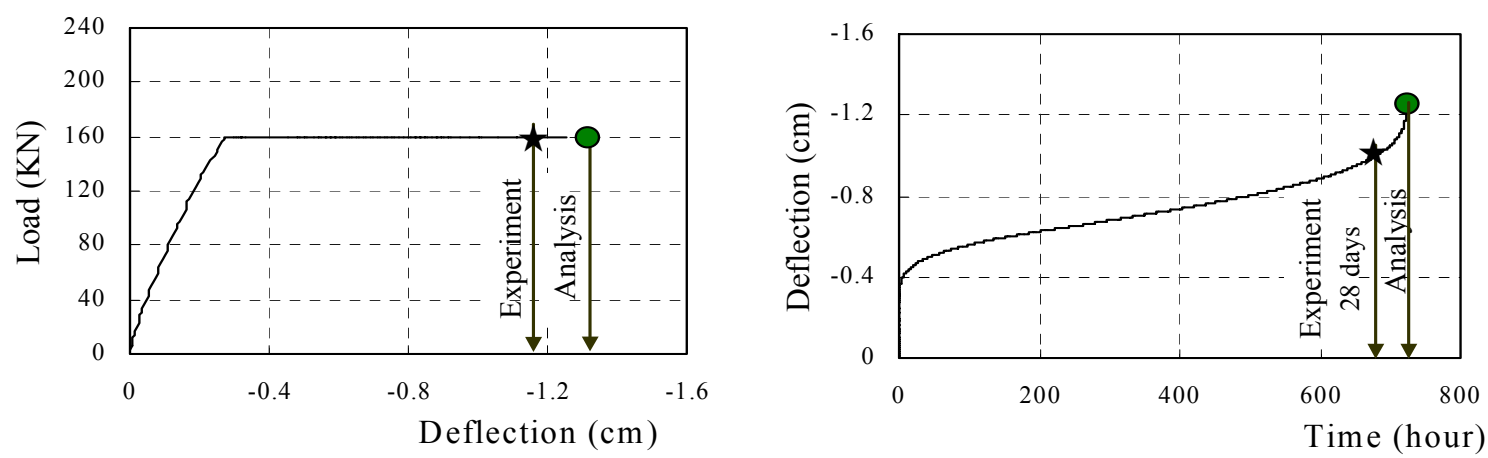

(c) Experimental and analytical results under sustained load

Fig. 3 Delayed creep failure of RC column in eccentric compression (no geometrical nonlinearity).

localized macro-scale crack is the target in the post-peak region within the referential control volume.

Formulation of the cumulative damage by cyclic mechanical action is discussed here in terms of fracture parameter ( $K$ in Eq. (4)). In fact, as shown in Fig. 1, degradation of unloading stiffness is seen during the repeated stress paths. It means that the fracture parameter denoted by $K$ in Eq. (4) changes by stress repetition as well as sustained load in continuum. Here, it is necessary to formulate the cyclic effect independently from the time-dependent evolution as stated in Chapter 1.

We also pay attention to the effect of stress or strain repetition on the development of plasticity. Apparently, progressive plastic strain is seen under cyclic loading, but it should be noted that some of the noticeable plastic evolution under cyclic loads can be caused by the cumulative damage resulting from stress repetition. Thus, it is not easy to solely extract the effect of cyclic mechanical action on plasticity. The authors therefore first formulate cumulative damaging and afterward verify the necessity of considering cyclic plasticity.

In order to include the effect of cyclic load into the main frame of the elasto-plastic and damaging model, the derivative of the fracture parameter regarding the path dependency (not time dependency) can be generalized as,

$$
\begin{aligned}
& \left(\frac{\partial K}{\partial \varepsilon_{e}}\right)=\lambda \quad \text { when } \mathrm{F}_{\mathrm{k}}<0, \\
& \left(\frac{\partial K}{\partial \varepsilon_{e}}\right)=-\left(\partial F_{k} / \partial \varepsilon_{e}\right) /\left(\partial F_{k} / \partial K\right)+\lambda \text { when } \mathrm{F}_{\mathrm{k}}=0
\end{aligned}
$$

where $\lambda$ is defined as fracture degradation rate to consider the effect of repetition of elastic strain, which indicates the stress intensity applied to the remaining effective volume (Okamura and Maekawa 1991). Since the fracture degradation rate is specified by the elastic strain, cumulative plasticity which is not avoidable in the experiments can be unconnected for the formulation of 

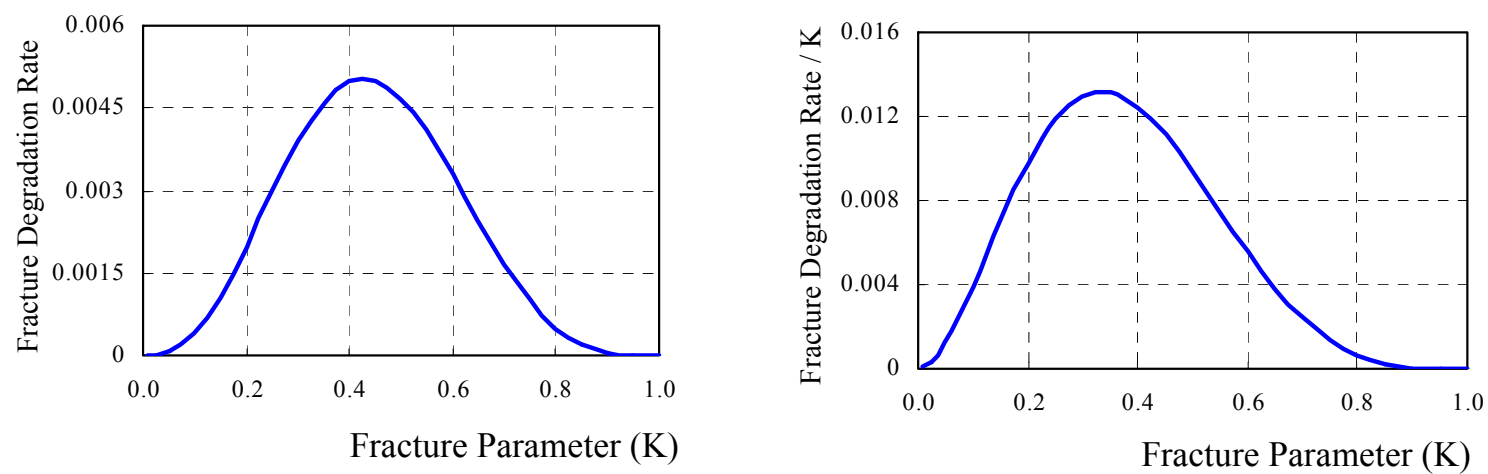

Fig. 4 Modeling of fracture degradation rate.

fatigue fracturing.

The fracture degradation rate is thought to be small when internal damage of the concrete continuum is low. In other words, the fracture parameter may be associated with the entire extension of micro-cracks when the parameter is between unity and 0.5 , a range where micro-defects can be assumed to be uniformly dispersed (Maekawa et al. 2003). Thus, the fracture degradation rate will be larger according to the progress of damaging $(1>K>0.5)$. The compressive damage localization occurs when the fracture parameter goes below 0.5 in the post-peak state. In this state, the effective volume where consequent damage can develop diminishes and the macroscopic fracture band is being built. Thus, the rate

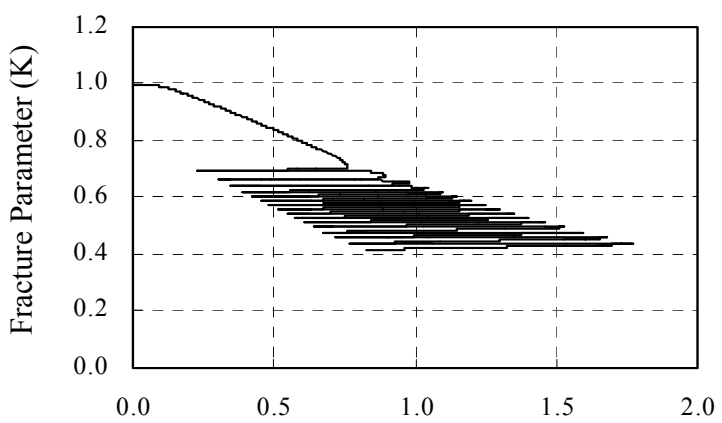

(a)

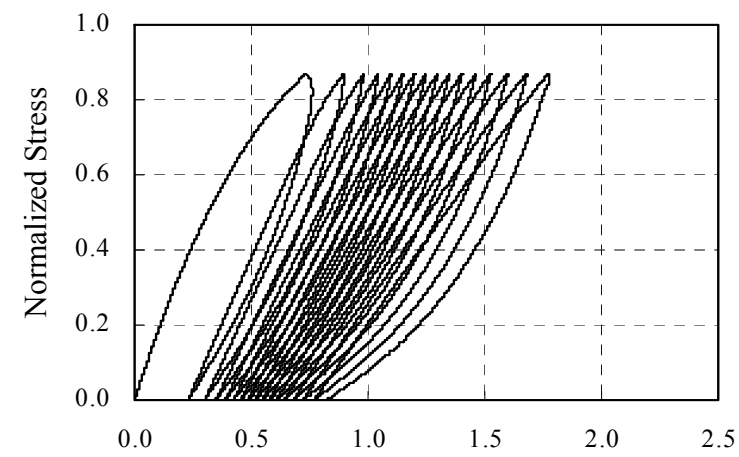

(c) of cumulative damaging in the post-peak region is thought to decelerate as illustrated in Fig. 4. As an extreme case, the progressive rate of damaging shall be null when the remaining effective volume (indicated by $\mathrm{K})$ which can bear stresses is completely lost $(\mathrm{K}=0)$. In considering these mechanics, the authors propose the following formula schematically expressed in Fig. $\mathbf{4}$ as,

$$
\begin{aligned}
& \lambda=K^{3} \cdot(1-K)^{4} \cdot \mathrm{g}, \\
& \mathrm{g}=0.6 \text { when } \mathrm{d} \varepsilon_{e}<0, \quad \text { otherwise, } \mathrm{g}=0
\end{aligned}
$$

where cumulative damaging is assumed to occur when relaxation of the internal stress intensity is performed. The amplitude of repetition is represented by the elastic

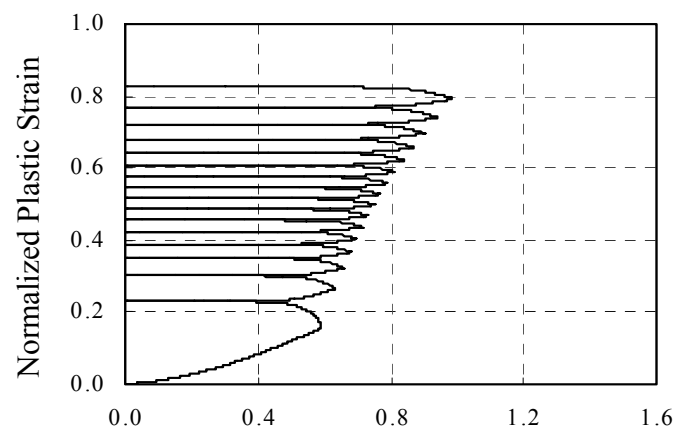

(b)

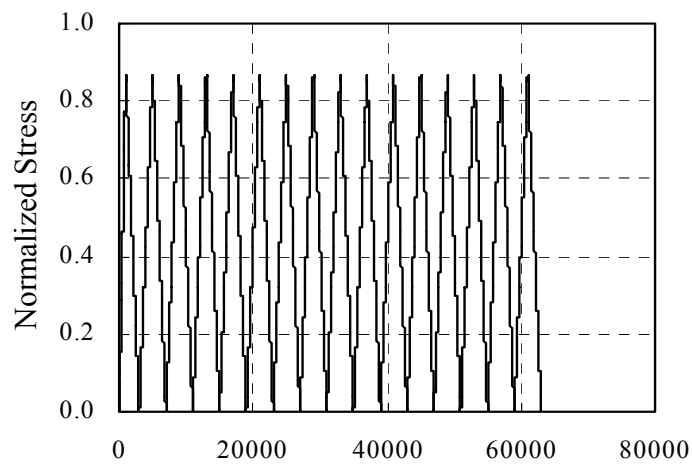

(d)

Time (s)

Fig. 5 Transient elasto-plastic and damaging path under cyclic constant amplitude of stress. 
strain increment. The rate of cumulative damaging per unit active volume that can substantially bear stress is also shown in Fig. 4. The fracture degradation rate reaches its highest value around $\mathrm{K}=0.4-0.5$ where compression softening may start. This corresponds to the fact that the rate of total strain accelerates greatly just before the fatigue failure even under constant stress amplitude. This is similar to the concrete creep failure, which can also be simulated by the elasto-plastic and damaging scheme (El-Kashif and Maekawa 2004)

This assumption yields the elasto-plastic and damaging paths as shown in Fig. 5 and Fig. 6. Under the constant amplitude of stress as shown in Fig. 5d, the total and plastic strains increase (see Fig. 5b and 5c) and the stiffness in each cycle gradually decreases. As the fracture parameter is steadily reduced as shown in Fig. 5a, the elastic strain correspondingly increases even though the maximum stress remains unchanged (see Fig. 5b). Here, the plasticity is accelerated in terms of time and instantaneous elastic strain path as formulated in Eq. (4). Thus, the accelerated plastic evolution by cyclic paths can be computed as shown in Fig. 5b just by considering the cumulative damaging of stress repetition with regard to $\mathrm{K}$.

Figure 6c shows the transient course of internal nonlinearity under a cyclic relaxation path on which the maximum total strain is kept constant. The damage progress leads to decay of both total stress and amplitude of elastic strain as shown in Fig. 6a. Even though the maximum elastic strain decreases, plastic evolution is computed to occur owing to the time-dependent term of

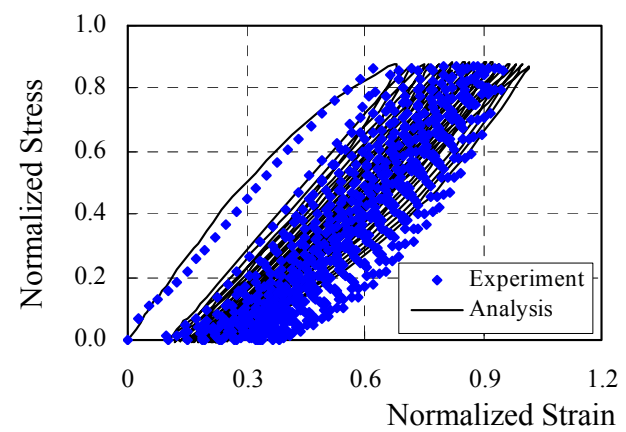

(a) Simulation by proposed model
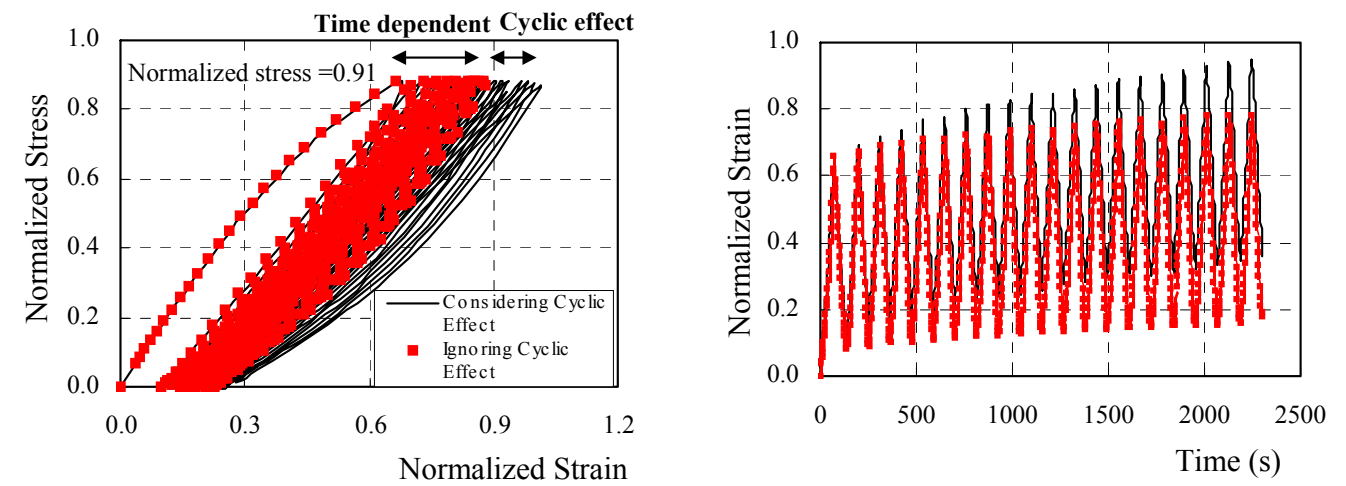

(b) Sensitivity analysis

Fig. 7 Verification of modeling under constant amplitude of stress. 
Eq. (4) and as shown in Fig. 6b. It is computationally confirmed that the cyclic plastic evolution can logically arise from the modeling of cyclic damaging. However, based on only the limited information discussed here, it is still not clear whether cyclic plasticity needs to be further implemented as a mechanics of concrete. This issue will be discussed through experimental verification in sections 3 and 4.

\section{Verification in plain concrete level}

In order to verify the proposed equation, experiments were selected to cover typical cases of structural analysis. As the post-peak behavior under cyclic loads represents the case of damaged structures close to collapse, it is essential to cover this area in practice. Figure 7a shows the analytical and experimental results of the specimen loaded at the age of 47 days with concrete compressive strength of $32.0 \mathrm{MPa}$. The comparison of the experimental and analytical results is also shown. A fair agreement between both results is noticeable. The computed result of the time-dependent nonlinearity alone is also shown in Fig. $\mathbf{7 b}$ for comparison. In fact, the derivatives of plasticity and damaging with respect to time were set equal to null in Eq. (2). It can thus be said that cyclic repetition should be mechanically considered as an independent solid characteristics of con- crete composite.

Figure 8a shows the analytical and experimental results of the concrete specimen loaded at the age of 54 days with uniaxial compressive strength of $32.0 \mathrm{MPa}$. The post peak cyclic relaxation path of stress decay is induced to a concrete cylinder with a height of $20 \mathrm{~cm}$. The stiffness declines to the extent that a large number of cycles is applied. When this specimen reaches the final cycle, the increment of stiffness degradation seems to be very small compared to the beginning of cycle loading. The computational model can predict the residual strain as well as the stiffness degradation. Consequently, the total strain progress can be observed as shown in Fig. 8a. The simulation of neglecting the cyclic effect but considering the time-dependent plastic and fracturing is shown in Fig. $\mathbf{8 b}$. The way of conducting sensitivity analysis is the same as the case of Fig. 7. Roughly speaking, $30 \%$ of the total stress decay is attributed to the time-dependent evolution of nonlinearity and the remaining $70 \%$ is associated with the effect of strain repetition.

Figure 9 shows the combined path of loading. When monotonic reloading is applied after large cyclic numbers, the stress-strain path is seen to come up to the envelope made by the pure monotonic loading from the beginning. This means that the cyclic cumulative evolution of fracture and plasticity may be renewed when the
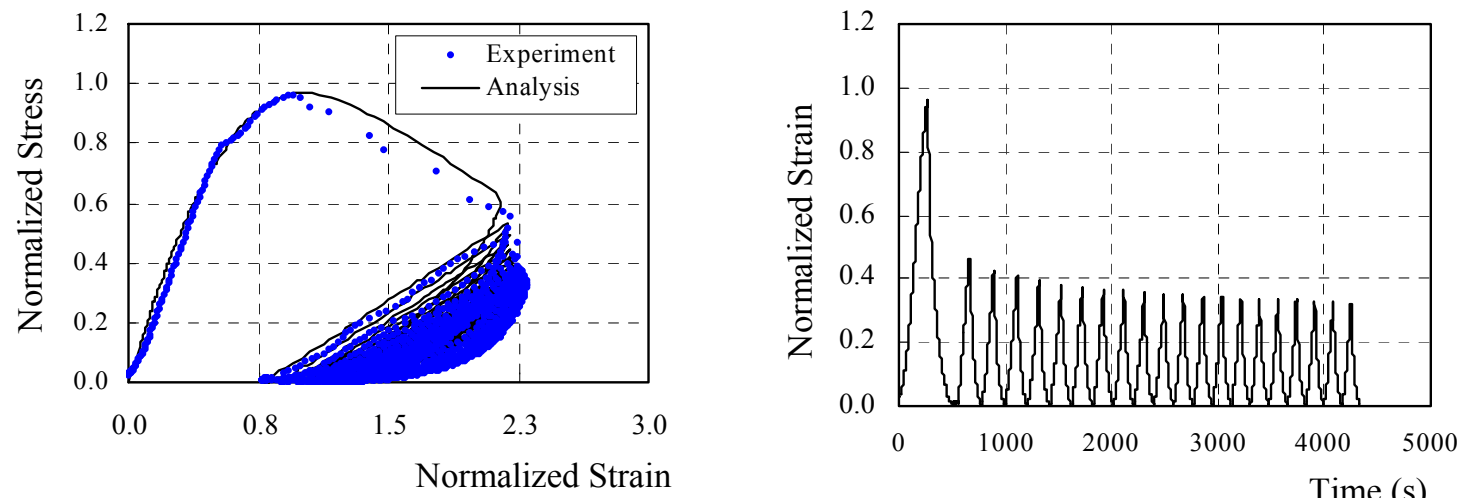

(a) Simulation by proposed model
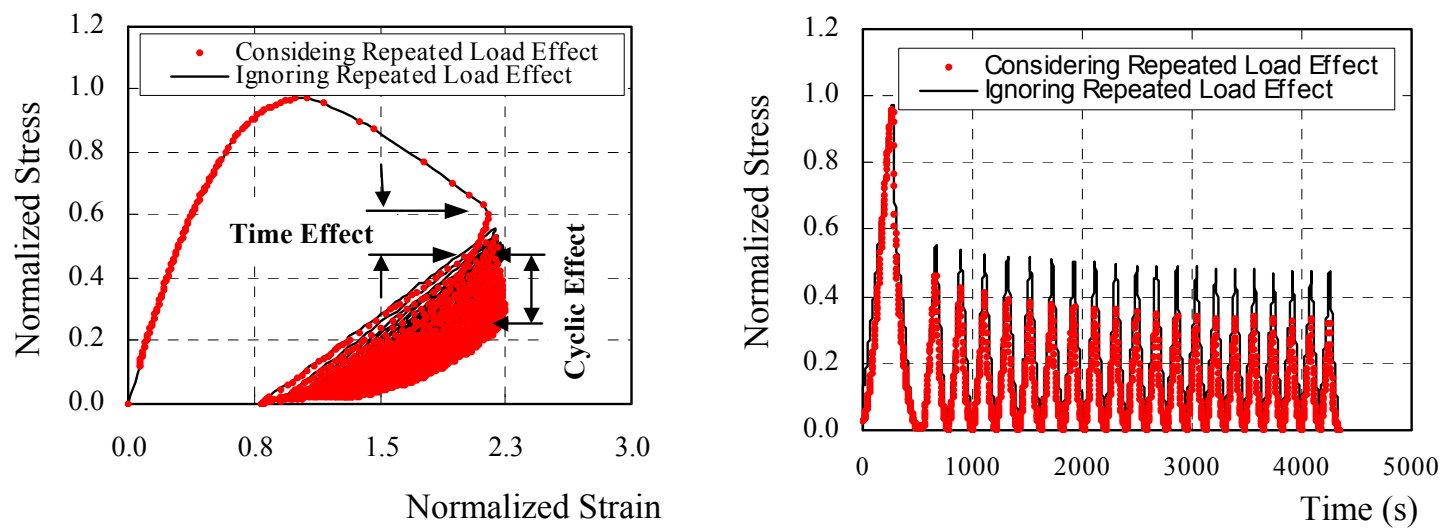

(b) Sensitivity analysis

Fig. 8 Verification of modeling under constant amplitude of strain. 

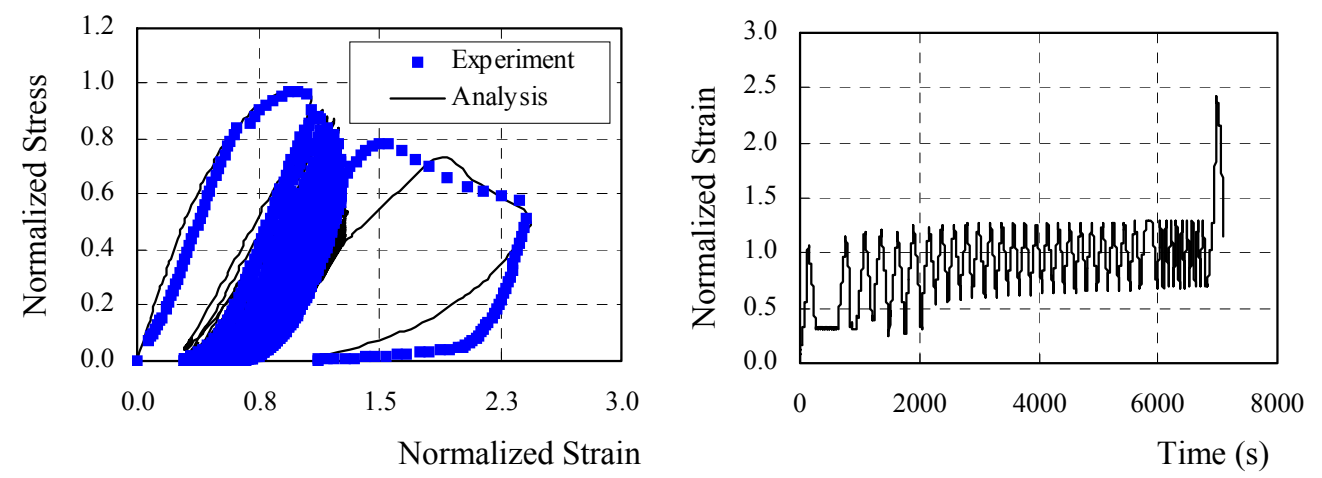

Fig. 9 Verification of modeling under varying amplitude of stress and strain.
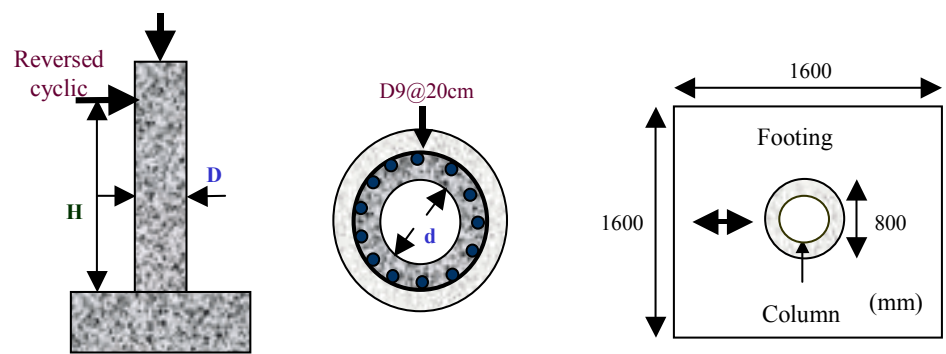

(a) Columns details
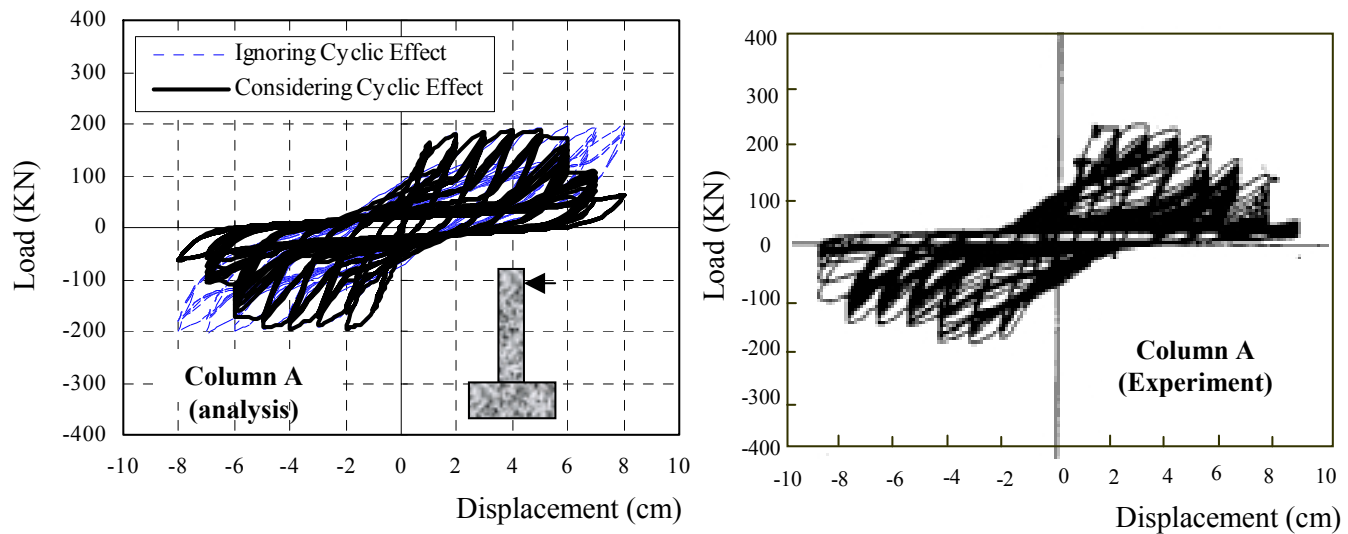

(b) Experimental and analytical results for column A
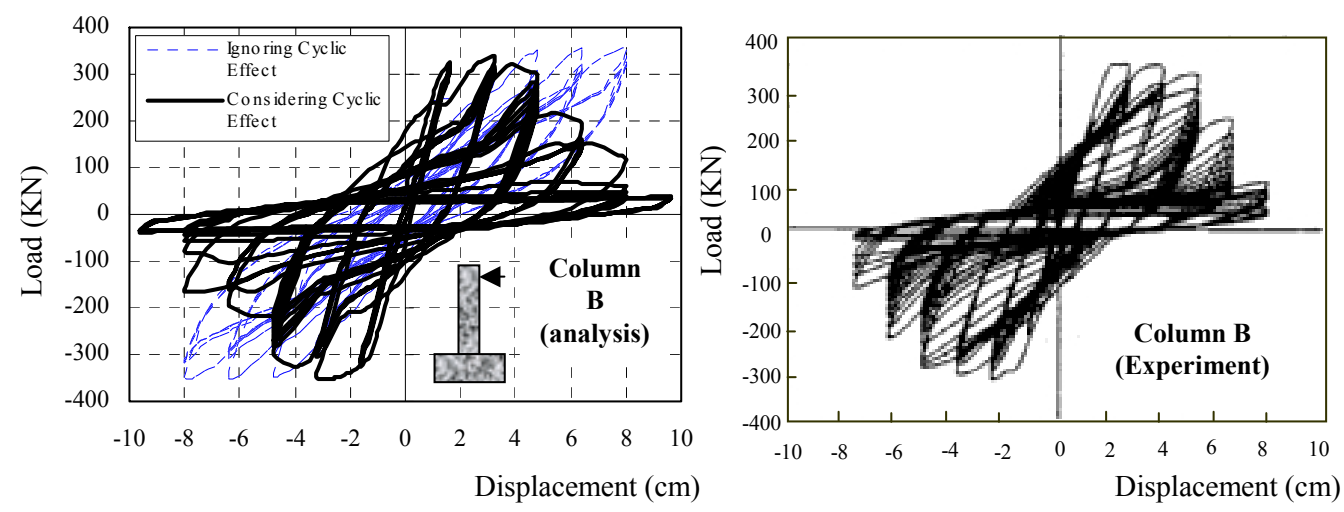

(c) Experimental and analytical results for column B

Fig. 10 Cyclic load effect on RC columns in flexure.

mechanical state exceeds the past maximum deformation and stresses to a large extent. The reasonable consistency of analytical and experimental results is recog- nizable on this sort of path-dependency. Thus, the authors deduced that the cumulative damaging of concrete under repeated action simulates the overall nonlinearity 
that appears at the material level. However, the evolution function of compressive damaging can be quantitatively improved in future especially in the post peak conditions where the rate of nonlinear evolution is comparatively high.

\section{Verification in structural level}

Overall behavior of reinforced concrete members has been investigated by introducing the stiffness degradations factor (Matsushima 1969, Takeda et al. 1970) so as to consider the effect of cyclic loads on shear failure. In addition, a quantitative assessment of damage has been presented through the use of damage indicators (Izuno et al. 1993). These indictors are usually defined in terms of ductility or energy-related factors. Recent experimental studies (El-Bahy et al. 1999, Kono et al. 2002, Park and Ang 1985) on RC members have led to empirical formulation that allows for concrete flexural resistance. However, the versatility of this sort of member-based approach is limited. In this chapter, pre- and post-peak computed responses of reinforced concrete under high cycles of external loads are investigated and experimental verification of the cyclic modeling is performed.

\subsection{Hollow section under cyclic loading for pre- and post-peak regions}

Experimental results (Kawashima 1992) of laterally confined RC columns are adopted for verification. Geometrical and mechanical properties of specimens A and B are shown in Fig. 10a and summarized in Table 1. Two columns with different amounts of reinforcement have a hollow circular cross section with an outer diameter of $80 \mathrm{~cm}$ and an inner diameter of $51.8 \mathrm{~cm}$. The columns were subjected to cyclic lateral displacement of a constant rate of $0.2 \mathrm{~cm} / \mathrm{min}$ at a height of $247.5 \mathrm{~cm}$. It was predicted that under large deformation and drift angle, spalling of the cover concrete might occur under cyclic deterioration. Two columns with different steel arrangement were cast continuously with rigid footings. The experimental results are shown in Fig. 10b.

The proposed time-dependent cyclic constitutive model of concrete in compression was imported into 3D fiber analysis (Maekawa et al. 2003). The pre- and postbuckling model of reinforcing bars developed by Dhakal (2002) is applied in the program to simulate the large deformation that occurs beyond the peak capacity. The size of finite element was selected to be the same as

Table 1 Dimensioning and detailing.

\begin{tabular}{|c|c|c|}
\hline & Column A & Column B \\
\hline Diameter $(\mathrm{cm})$ & 80 (outer) & 80 (outer) \\
\hline Main reinforcement & $30-\mathrm{D} 10$ & $30-\mathrm{D} 13$ \\
\hline Cover thickness & $5 \mathrm{~cm}$ & $5 \mathrm{~cm}$ \\
\hline Comp. strength & $35.4 \mathrm{MPa}$ & $34.9 \mathrm{MPa}$ \\
\hline Tensile strength & $1.50 \mathrm{MPa}$ & $1.50 \mathrm{MPa}$ \\
\hline Young's modulus & $206 \mathrm{GPa}$ & $206 \mathrm{GPa}$ \\
\hline Yield strength & $635.0 \mathrm{MPa}$ & $635.0 \mathrm{MPa}$ \\
\hline
\end{tabular}

the size of referential volume of $20 \mathrm{~cm}$ on which the averaged stress strain relation of concrete is formulated. Thus, adaptation of constitutive model in terms of compressive fracture energy is not necessary (Lettsrisakulrat et al. 2000). Figure 10c shows the computed results.

As the buckling could not be visually observed in reality, the strength deterioration can be mainly attributed to the time-dependent cyclic damaging and spalling of cover concrete. As can be seen in Fig. 10, the analysis could successfully capture the strength degradation, load and deformation at the peak and post peak responses, respectively. A softening branch followed by cyclic degradation can be seen. The stress decay under the constant amplitude of enforced displacement is significant in the post-peak state and well simulated by the cyclic modeling. However, if the cumulative damage by cyclic action is ignored in the analysis $(\lambda=0$ in Eq. (5)) as shown in Fig. 10, the stress degradation by stress iteration becomes much milder and greatly deviates from reality. Thus post-peak degradation cannot be explained only by the time dependent progress of nonlinearity in this case.

\subsection{Shear wall under cyclic loads with different rate of displacement}

In this section, experimental verification of timedependent cyclic modeling is discussed based upon inplane problems. Esaki et al. (2001) investigated the rate effect on the restoring force characteristics of RC shear walls subjected to highly reversed cyclic actions and concluded that time dependency is hardly identical in comparisons with the reproducibility of experiments. This experimental fact may be satisfactorily close to the capacity of shear wall structures and the same conclusion is applicable to other RC structures in view of seismic response (Mutsuyoshi and Machida 1985).

However, this issue is questionable in the transient states of collapse after the peak. Matsuoka and Ono et al. (2001) intensively conducted cyclic loading experiment of shear walls under different rates of displacement covering the post-peak regions, and reported that the restoring force characteristics are influenced practically in accordance with the rate of loading. As the softening of $\mathrm{RC}$ in-plane panels is directly associated with compression softening of concrete along cracking, the post-peak cyclic behaviors of time dependency are appropriate for verification. Thus, the authors imported the proposed time-dependent cyclic constitutive model of concrete in compression into the nonlinear finite element code (Maekawa et al. 2003, Okamura and Maekawa 1991).

The in-plane RC constitutive law consists of submodels as shown in Fig. 11. The uniaxial stress-strain relation of concrete is applied to the stress carrying mechanism along cracks. The original multi-directional fixed crack modeling (Maekawa et al. 2003) employs elasto-plastic and fracturing law of concrete in compression. Since the newly enhanced computational model concerning time dependency and cumulative damage of 


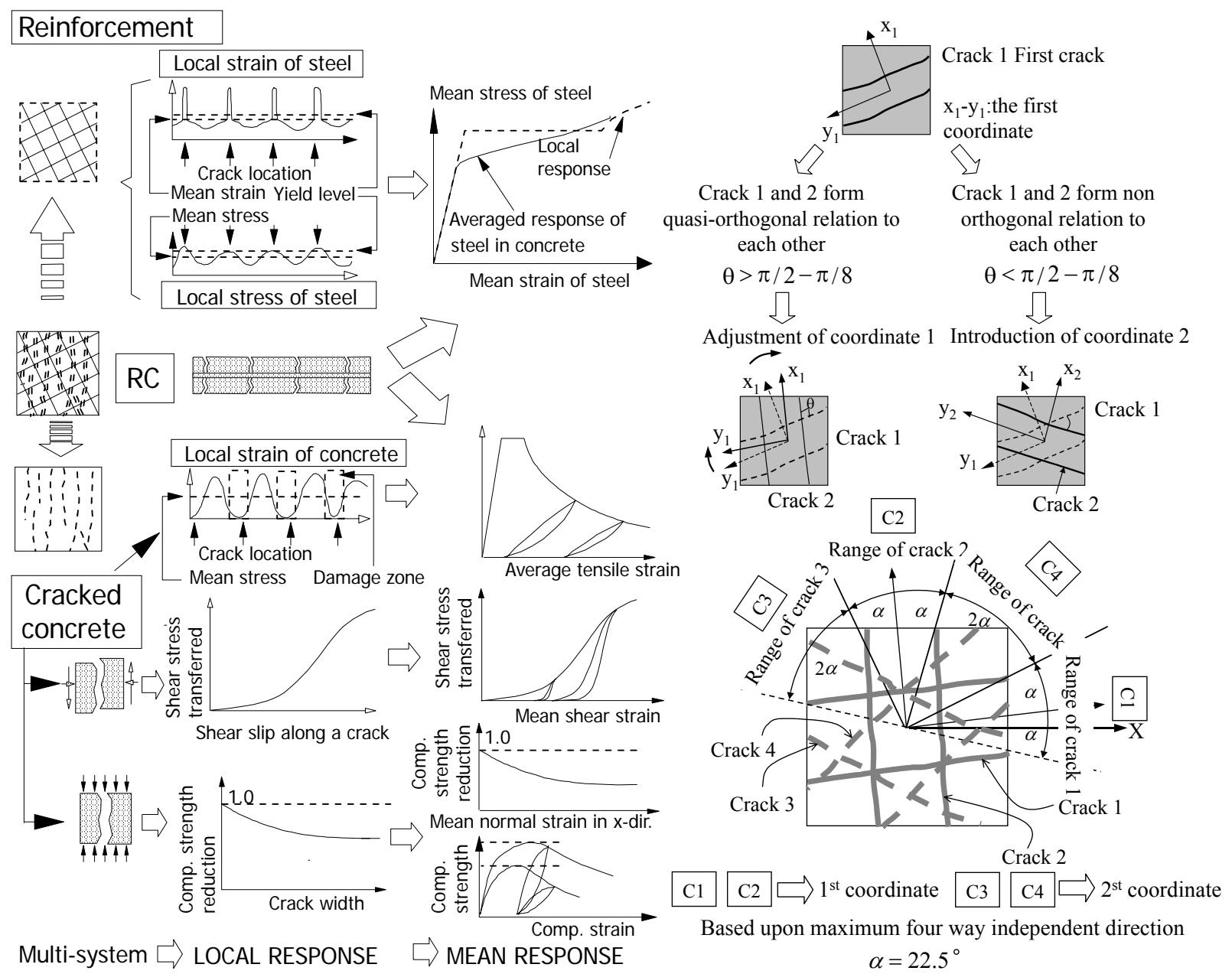

Fig. $11 \mathrm{RC}$ in-plane constitutive modeling and multi-directional cracking.

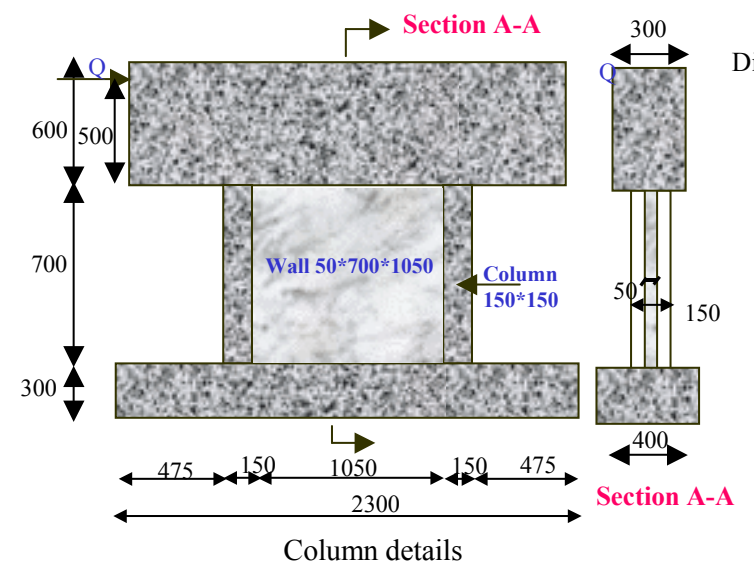

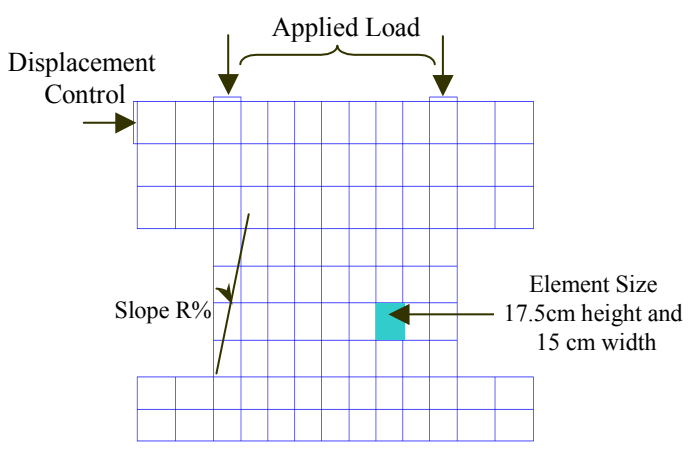

Finite element used and boundary conditions

Fig. 12 Detailing of shear wall and finite element discretization.

repeated action is built up on the same scheme of nonlinear mechanics as the original, simple replacement of the subroutine was required and sufficient. In this formulation, the tension stiffness and shear transfer of cracked concrete are unchanged and remain timeindependent. In fact, the time dependency of tension stiffness was reported to be negligibly small in shortterm loadings for ultimate limit state computation. As isotropically arranged RC panels subjected to simple inplane shear are not affected by the shear transfer along cracks, shear transfer can be left out discussion for popular RC shear wall designs under low cycle fatigue. The post-buckling model of reinforcement is not necessary for this analysis because the absolute deformation of in-plane walls is limited. For reversed cyclic loads, multi-directional cracking is created within the individ- 
ual finite element as shown in Fig. 11. In this case, crack-to-crack interaction with respect to shear slip along each crack plane is strictly taken into account within the scheme of active crack method proposed by Okamura and Maekawa (1991).

Figure 12 shows the shear walls experimented by Matsuoka and Ono et al. (2001) and used for verification of the modeling. The details of shear walls are summarized in Table 2. Finite element discretization and the loading point are indicated together. Computed and experimental shear forces versus drift angle relations are shown in Fig. 13 under monotonic loading. In general, the computed results match the experiments in both pre and post peak states under three levels of deformational rates $(0.01,0.10,1.00 \mathrm{~cm} / \mathrm{sec})$. The capacity of the shear walls is slightly influenced by the loading rate. The high speed loading gives rise to the greater capacity in reality. However, the analysis shows almost the same capacity and similar restoring force characteristics. As the yield of reinforcement is one of the limit states of this shear wall and the compressive strength of concrete plays a minor role in the capacity, the experimental capacity gain is thought to be caused by the strain rate effect on yield strength of reinforcement (Cowell 1965, Malvar 1998). In Fig. 13d, the simulation results are shown with $10 \%$ increased yield strength of reinforcement for sensitivity analysis. The strength gain

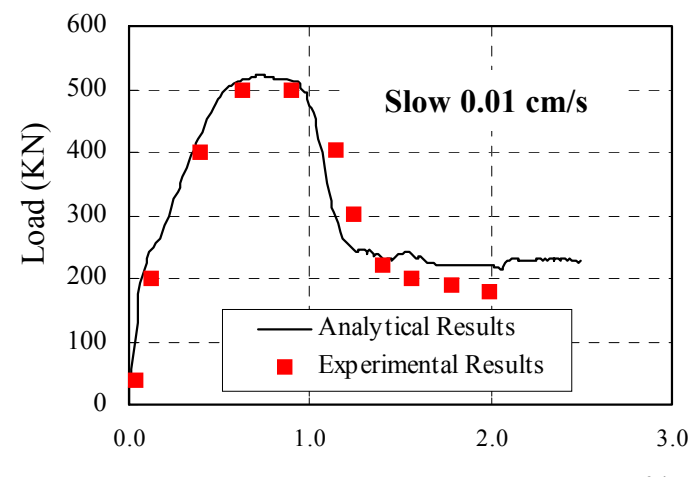

(a) Slow rate

$\mathrm{R} \%$

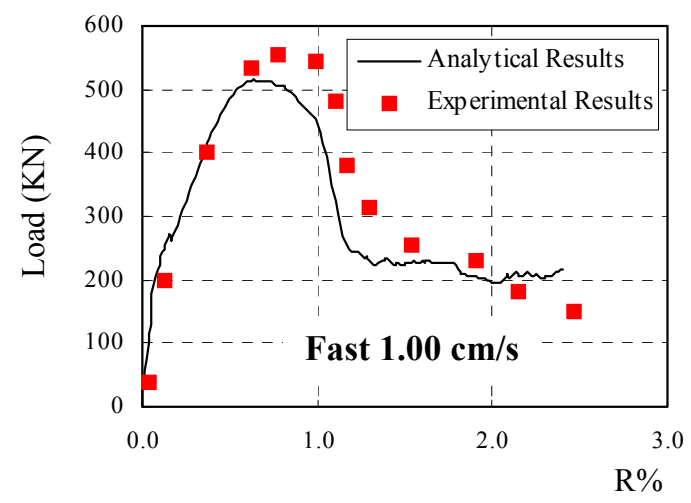

(c) Fast rate
Table 2 Experiments details of shear walls.

\begin{tabular}{|c|c|c|c|c|}
\hline Wall & $\begin{array}{l}\text { Load pat- } \\
\text { tern }\end{array}$ & $\begin{array}{l}\mathrm{R} / \mathrm{F}: \text { side } \\
\text { column }\end{array}$ & $\mathrm{R} / \mathrm{F}$ : wall & $\begin{array}{c}\text { Compressive } \\
\text { strength }\end{array}$ \\
\hline 1 & Monotonic & \multirow{3}{*}{$\begin{array}{l}3.40 \% \text { in } \\
\text { longi. dir. } \\
\text { fy=334MPa } \\
0.33 \% \text { in } \\
\text { horiz. dir. } \\
\text { fy }=178 \mathrm{MPa}\end{array}$} & \multirow{3}{*}{$\begin{array}{c}0.50 \% \text { in } \\
\text { both dir. } \\
\text { fy= }=178 \mathrm{MPa} \\
\text { Diameter } \\
4 \mathrm{~mm}\end{array}$} & $26.5 \mathrm{MPa}$ \\
\hline 2 & Cycle 1 & & & $27.7 \mathrm{MPa}$ \\
\hline 3 & Cycle 2 & & & $27.7 \mathrm{MPa}$ \\
\hline
\end{tabular}

$\mathrm{R} / \mathrm{F}$ : reinforcement ratio, fy $=$ yield strength

under the fast loading rate can be explained by the increase in yield strength of reinforcement. However, the compression modeling of concrete is of importance in the post-peak regions. Thus, in both experiment and analysis, the rate effect on the post-peak ductility is not clearly identical under monotonic loads as discussed in the past.

For shear walls of the same dimension and detailing, the reversed cyclic shear was applied under different rates of loading (slow $=0.01$, middle $=0.10$, fast $=1.00$ $\mathrm{cm} / \mathrm{sec}$ ) as shown in Fig. 14. Type B presents the path of large numbers of repetition. Consequent pre and post peak responses are shown in Fig. 15. The single sided results are exhibited as symmetry of load-displacement curves is shaped. For comparison, the simulation results of neglecting the cumulative damage by cyclic paths (only time-dependent deformation is considered) are
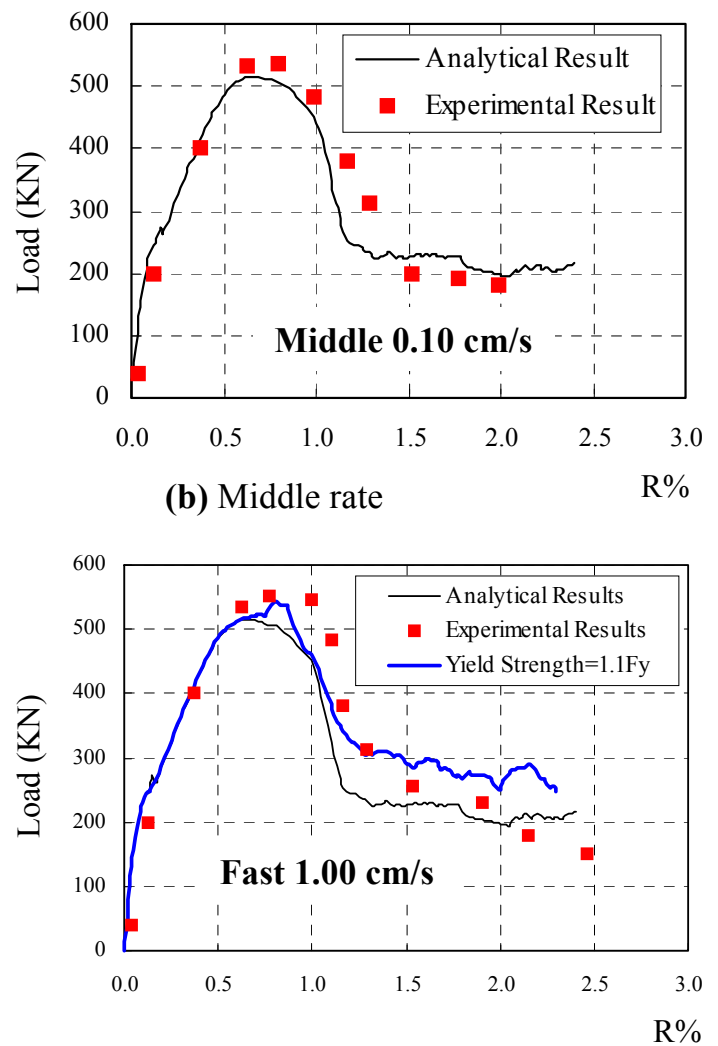

(d) Effect of yield strength of steel

Fig. 13 Computational and experimental relations of monotonic shear force versus deformation. 

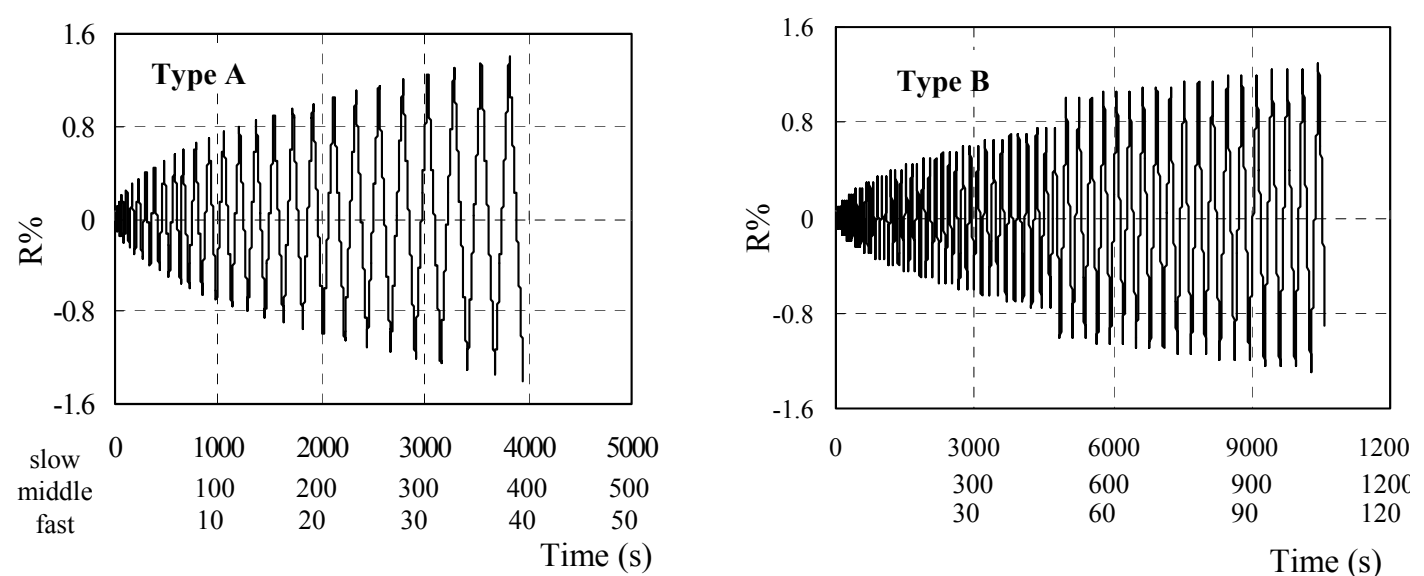

Fig. 14 Applied shear deformation under different rates of loading.

presented together. The coupling of the effect of strain cycles with time dependency improves the accuracy of the analytical post-peak responses. For simulating the response until capacity is reached, it seems that cyclic effect is negligibly small.

In order to check the cyclic effect in more detail, high cycle of loading was investigated as shown in Fig. 16. Total numbers of repetitions are larger than in the cases of Fig. 15 and the decay of restoring forces after the peak capacity is greater and the larger deviation of residual shear force from the monotonic loading cases can be seen in both experiment and analysis. It can be concluded that the cyclic damaging model of concrete is significant especially in the post-peak states accompanying the localization of compressive deformation rather than the effect of loading rate. Thus, the coupling of the time effect with the cyclic cumulative damage is substantial for purely extracting the effect of repetition, which is of greater practical importance for actual seismic analyses of wall-type structures than the time effect.

\section{Application to high cycle fatigue}

As the proposed model is mainly aimed to simulate the

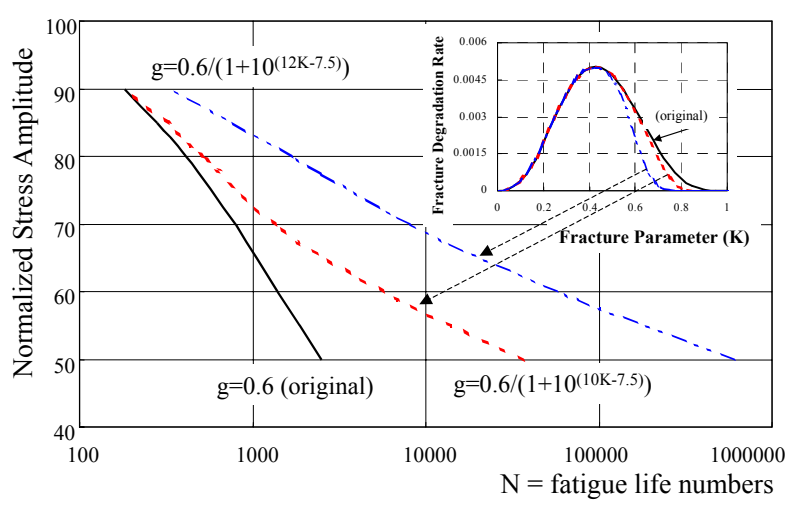

Fig. 17 Computational high cycle fatigue life based on the fracturing degradation model. post-peak failing process of structures, high cycle fatigue loads under serviceable stress levels are not apparently considered. Figure 17 shows the computed fatigue life (numbers of repetition) in the form of an S-N curve under high stress rate $(1.0 \mathrm{~Hz})$. It can be seen that the smaller stress amplitude in compression leads to exponentially longer life in computation, which is similar to reality. However, the proposed model deviates from the JSCE design formula when the number of cycles exceeds 100 cycles. Thus, the proposed model may lead to safer evaluation of failure risk although this model is not intended to embrace high cycle fatigue.

Under middle or lower stress levels, the effect of time dependency of deformational nonlinearity on the computed fatigue life is comparatively small and the computed cycle numbers are mostly dependent on the model of fracturing degradation factor in Eq. (6). For trial, a parametric study was conducted in terms of fracturing the degradation factor and the parameter $\mathrm{g}(=0.6)$ in Eq. (6) was empirically found to be convertible to the high fatigue S-N curve of concrete as,

$$
\mathrm{g}=0.6 /\left(1+10^{\beta \cdot \mathrm{K}-7.5}\right), \beta=10 \sim 12
$$

The modified function by Eq. (7) for smaller stress state is shown in Fig. 17. The slight change of fracturing degradation factor is influential on the high cycle fatigue life under smaller stress states. Further investigation for high cycle fatigue model is required and the accuracy of the fracturing degradation factor under less damaged conditions shall be improved for greater versatility of modeling in future. However, as far as low cycle failure problems $(\mathrm{N}<100$ cycles) are concerned (e.g., post-peak seismic analyses), time dependency is not negligible but Eq. (6) is proposed.

\section{Conclusions}

(1) Uniaxial cyclic stress/strain paths were applied to concrete cylinders and the overall evolution of plasticity and damaging was experimentally investi- 

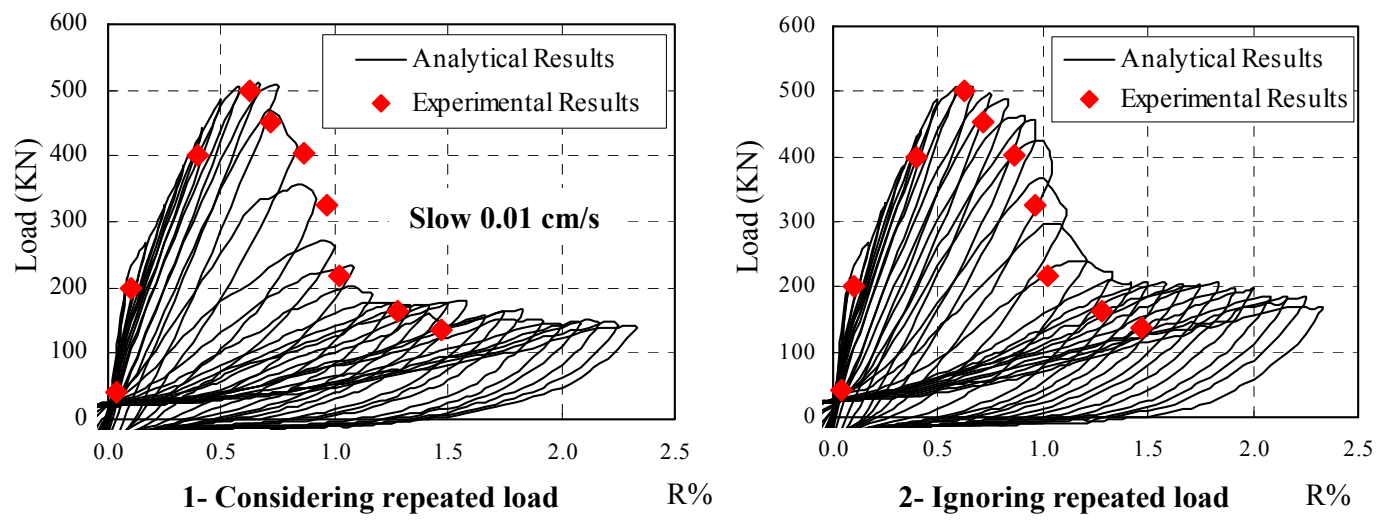

(a) Slow rate of loading

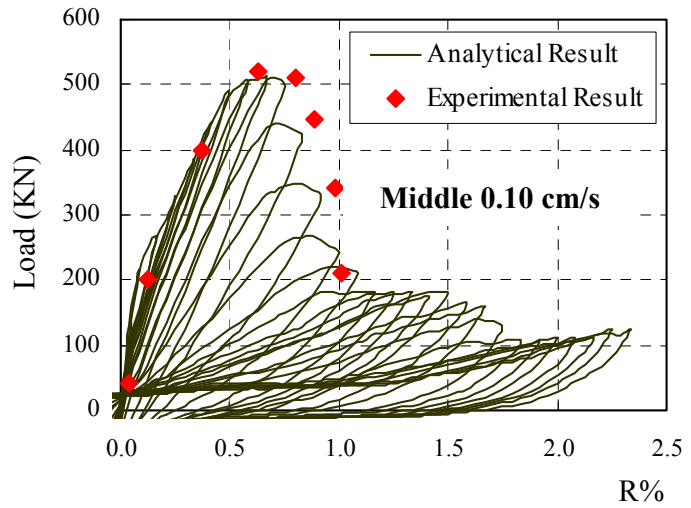

1- Considering repeated load

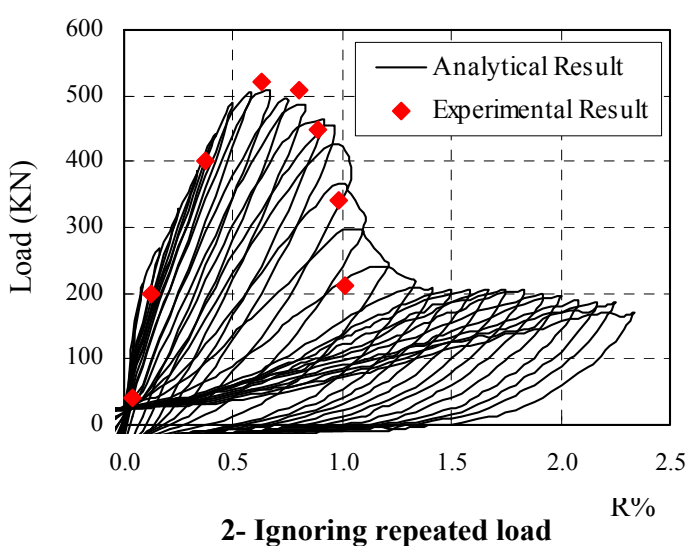

(b) Middle rate of loading
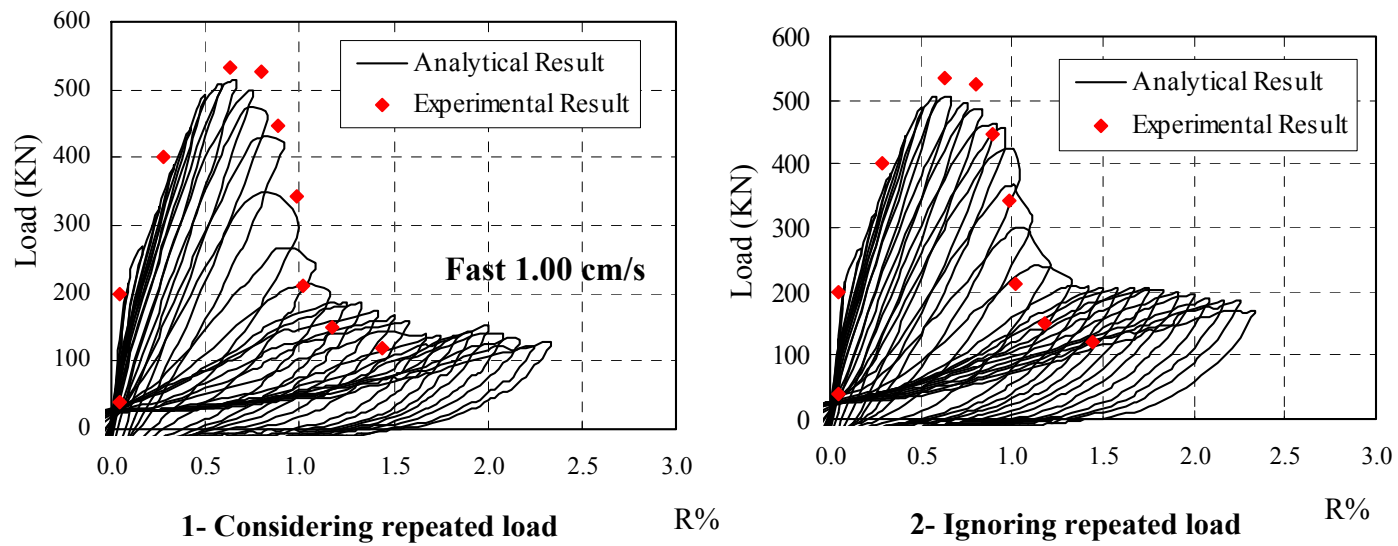

(c) Fast rate of loading

Fig. 15 Computational and experimental relations of cyclic shear force versus deformation (Type A loading).

gated. Constant stress amplitude, cyclic relaxation and their combination were selected in the pre and post-peak regions where short-term time dependency is predominant.

(2) For actuated stress/strain paths, time-dependent plastic and damaging were computed by using the short-term elasto-plastic and damaging model and the effect of repetition of stresses was purely extracted. In the extraction process, the short-term time dependent model was verified at the structural level as well as the material level.

(3) The repetition of stresses was successfully represented by a fracture parameter that indicates the degradation ratio of unloading stiffness. Apparent plastic evolution by cyclic stress paths was mechanically explained as a resultant increment of plasticity from the evolution of fracture parameter caused by stress cycles. 

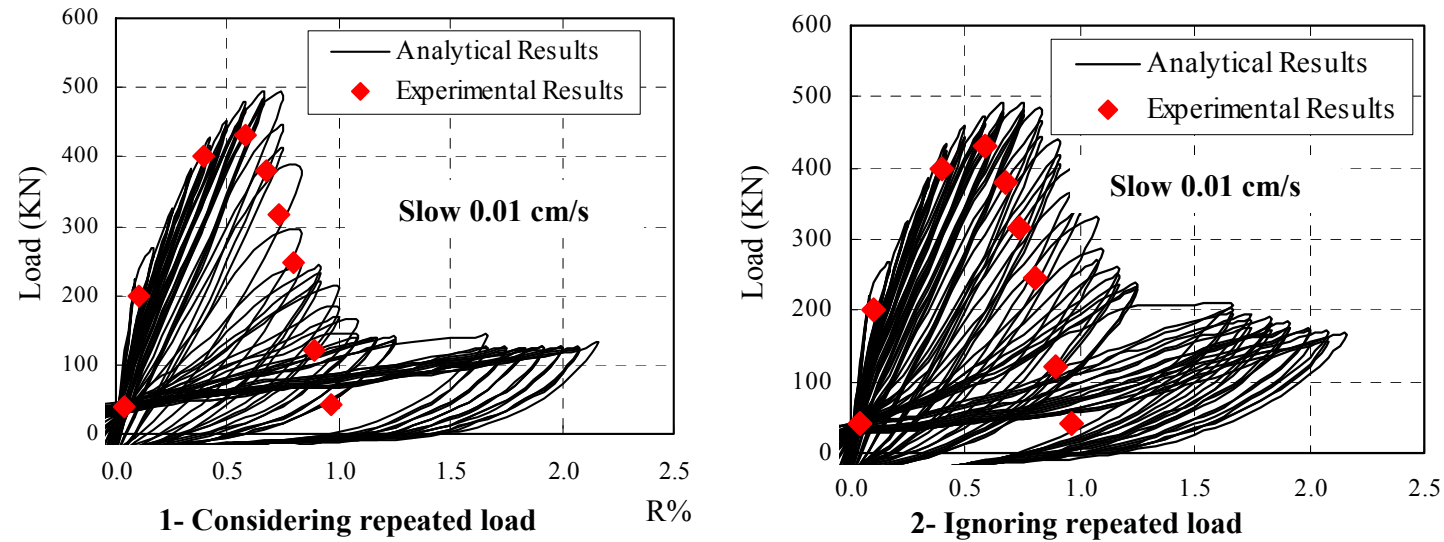

(a) Slow rate of loading
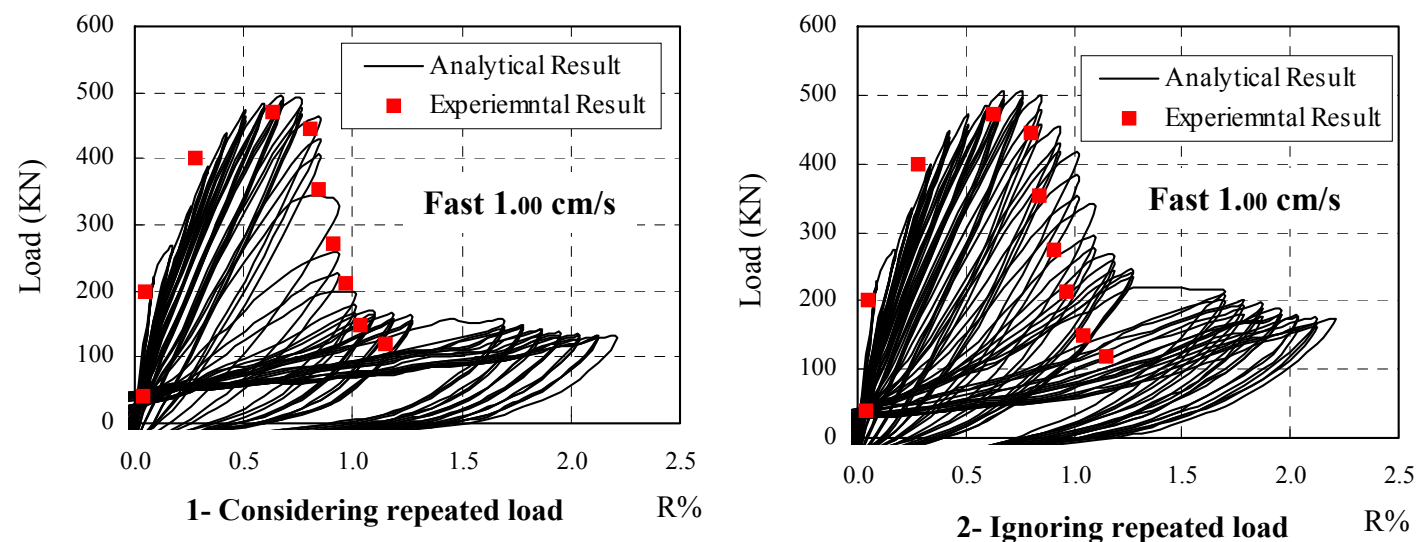

(b) Fast rate of loading

Fig. 16 Computational and experimental relations of cyclic shear force versus deformation (Type B loading of large numbers of cycles).

(4) The formulated time-dependent cyclic constitutive model was experimentally verified by using materials and RC in-plane walls subjected to reversed cyclic shear with different rates of loading.

(5) Extension of the proposed low cycle timedependent constitutive modeling to high cycle fatigue was discussed for future progress.

\section{Acknowledgments}

The authors appreciate fruitful and valuable discussion with Dr. T. Ishida and Dr. T. Kishi of The University of Tokyo. This study was financially supported by Grantin-Aid for Scientific Research (S) No.15106008.

\section{References}

Claeson, C. and Gylltoft, K. (2000). "Slender concrete column subjected to sustained and short-term eccentric loading." ACI Structural Journal, 97 (1), 45-52.

Cowell, W. L. (1965). "Dynamic tests of concrete reinforcing steels." Technical Reports R384, Naval Civil Engineering Laboratory, Port Hueneme, Calif., September.

Dhakal, R. P. and Maekawa, K. (2002). "Modeling for post-yield buckling of reinforcement bar including buckling." Journal of Structural Engineering, ASCE, 128 (9), 1139-1147.

El-Bahy, A., Kunnath, S. K., Stone, W. C. and Taylor, A. W. (1999). "Cumulative seismic damage of circular bridge columns: Benchmark and low-cycle fatigue tests." ACI Structural Journal, 96 (4), July-August.

El-Kashif, K. F. and Maekawa, K. (2004). "Timedependent nonlinearity of compression softening in concrete." Journal of Advanced Concrete Technology, 2 (2), 233-247.

El-Kashif, K. F. and Maekawa, K. (2003). "Computational model for time-dependent compressive behavior based on plasticity and fracturing approach." JCI Proceedings, 25 (2), 145150.

El-Kashif, K. F. and Maekawa, K. (2003). "Timedependent compressive deformation and post-peak softening for concrete." Proc. of Response of Structures to Extreme Loading Conference, Toronto.

Esaki, F. and Ono, M. (2001). "Effect of loading rate on mechanical behavior of SRC shear walls." Steel and composite structures, 1 (2), 201-212.

Gao, L. and Hsu, T. T. C. (1998). "Fatigue of concrete 
under uniaxial compression cyclic loading." $A C I$ Structural Journal, 95, 575-581.

Hsu, T. T. C. (1981). "Fatigue of plain concrete." $A C I$ Journal, 88 (4), 292-305.

Hwan, O. B. (1991). "Fatigue life distributions of concrete for various stress levels." ACI Material Journal, 88 (2), 122-128.

Izuno, K., Iemura, H., Yamada, Y. and Fujisawa, S. (1993). "Seismic damage assessment of RC structures using different hysteretic models." Memories of The Faculty of Engineering, Kyoto University, 55 (1), 119.

Kawashima, K. (1992). "Dynamic strength and ductility of hollow circular cross reinforced concrete bridge pier.” JCI Proceedings, 34-39. (In Japanese)

Kono, S., Bechtoula, H., Kaku, T. and Watanabe, F. (2002). "Damage assessment of RC columns subjected to axial load and bi-directional bending." JCI Journal, 24 (2), 235-240. (in Japanese).

Lettsrisakulrat, T., Watanabe, K., Matsuo, M. and Niwa, J. (2000). "Localization effects and fracture mechanism of concrete in compression." JCI Proceedings, 22 (3), 145-150.

Maekawa, K, Pimanmas, A. and Okamura, H. (2003). "Nonlinear Mechanics of Reinforced Concrete." SPON Press, London.

Maekawa, K., Li, B. and Odagawa, M. (1984). "Influence of time and stress-strain path on deformation characteristic of concrete and its analytical model." Symposium on FEM Analysis of $R C$ Structure, JCI, 11-18. (in Japanese)

Malvar, L. J. (1998). "Review of static and dynamic properties of steel reinforcing bars." ACI Material Journal, 95 (5), 609-616.

Matsuoka, R., Ono, M. and Esaki, F. (2001). "Cyclic effect and loading rate on the mechanical behavior of shear walls." JCI Proceedings, 433-438. (in Japanese)

Matsusima, Y. (1969). "A Study of hysteresis model from damage caused by Tokachi-Oki Earthquake." Summaries of Technical Papers of Annual Meeting, AIJ, 587-588.

Mutsuyoshi, K. and Machida, A. (1985). "Behavior of reinforced concrete members subjected to dynamic loading." Journal of Materials, Concrete Structures and Pavements, JSCE, 354/V-2, 81-90.

Okamura, H. and Maekawa, K. (1991). "Nonlinear Analysis and Constitutive Model of Reinforced Concrete." Giho-do Press, Tokyo.

Park, Y. J. and Ang, A. H. S. (1985). "Mechanistic seismic damage model for reinforced concrete." Journal of Structural Engineering, ASCE, 111 (4), 722-739.

Tabata, M. and Maekawa, K. (1984). "Prediction model for plasticity and failure of concrete based on time dependence." JCI Proceedings, 269-272. (in Japanese)

Takeda, T., Sozen, M. A. and Nielsen, N. N. (1970). "Reinforced concrete response TZO simulate earthquake." Journal of Structural Division, ASCE, 96 (12), 2257-2573.

Viest, I. M., Elstner, R. C. and Hognestad, E. (1956). "Sustained load strength of eccentrically loaded short reinforced concrete column." ACI Journal, 27 (7), 727-755. 